in vivo $31: 387-395(2017)$

doi:10.21873/invivo.11071

\title{
Magnetic Resonance Imaging Assessment of Lipomatous Soft-tissue Tumors
}

\author{
ALESSANDRO CORAN ${ }^{1}$, PAOLO ORTOLAN ${ }^{2}$, SHADY ATTAR $^{2}$, ENRICO ALBERIOLI $^{2}$, \\ EGLE PERISSINOTTO ${ }^{3}$, ANNA LISA TOSI ${ }^{4}$, MARIA CRISTINA MONTESCO ${ }^{4}$, \\ CARLO RICCARDO ROSSI ${ }^{5}$, SAVERIA TROPEA ${ }^{5}$, MARCO RASTRELLI ${ }^{5}$ and ROBERTO STRAMARE ${ }^{2}$ \\ ${ }^{1}$ Department of Radiology and Medical Physics, Oncologic Radiology Unit, \\ Veneto Institute of Oncology, IOV-IRCCS, Padua, Italy; \\ ${ }^{2}$ Department of Medicine, Radiology Unit, University of Padova, Padua, Italy; \\ ${ }^{3}$ Department of Biostatistics, Public Health Unit, University of Padova, Padua, Italy; \\ ${ }^{4}$ Department of General Health Services, Pathology Unit, Veneto Institute of Oncology, IOV-IRCCS, Padua, Italy; \\ ${ }^{5}$ Department of Surgical Oncology, Surgical Oncology Unit, Veneto Institute of Oncology, IOV-IRCCS, Padua, Italy
}

\begin{abstract}
Aim: To establish the accuracy of magnetic resonance imaging (MRI) in distinguishing between benign and malignant lipomatous tumors; to evaluate the reproducibility of the MRI interpretation assessing the agreement between judgments of two radiologists with the same experience in soft-tissue sarcomas; to identify an association among MRI findings (size, depth, septa, nodules, signal homogeneity) and nature of the lesion. Materials and Methods: A total of 54 patients (28 men and 26 women), with a mean age of 56 (range $=27-84$ ) were included years. All subjects followed-up by the Multidisciplinary Sarcoma Group. The following MRI findings were judged in a blind study by two radiologists: size, localization, septa, nodules and signal homogeneity. A diagnostic indication was then given from among lipoma, atypical lipomatous tumour (ALT) and liposarcoma. Accuracy in distinguishing between benign and malignant lesions, and between lipoma and ALT (Fisher's exact test), inter-operator agreement (Cohen's kappa), association of MRI findings and malignancy of the lesion (Fisher's exact test and odds ratio) were evaluated. Results: The inter-operator agreement was complete (100\%). The agreement between diagnostic hypothesis and histological diagnosis was statistically significant $(p<0.05)$. Among the radiological findings taken into account, only septa and signal homogeneity were significantly associated with the malignancy of the lesion $(p<0.05)$. Conclusion: MRI
\end{abstract}

This article is freely accessible online.

Correspondence to: Marco Rastrelli, Via Gattamelata, 64, 35128 Padova (PD), Italy. Tel: +39 0498212137, e-mail: marco.rastrelli@iov.veneto.it

Key Words: Sarcoma, liposarcoma, lipoma, MRI. could be helpful in distinguishing lipomatous tumors, allowing biopsy to be avoided in some cases (negative predictive value $=100 \%$ ).

Adipocytic tumors are tumors of mesenchymal origin, which can be either benign (lipoma, lipomatosis, etc.) or malignant (liposarcomas). Liposarcomas are rare tumors of mesenchymal origin and are the second most common subgroup of softtissue sarcomas in adults, with a peak age of incidence between the fifth and seventh decade $(10-35 \%)(1,2)$.

In 2013, the World Health Organization (WHO) Committee for classification of soft-tissue tumors revised the classification, dividing the category of liposarcomas into five histological subtypes: well-differentiated (or atypical lipomatous tumor), dedifferentiated, myxoid, pleomorphic and mixed. This classification is a precise differentiation of morphological and biological activity of the disease, with a behavior that can range from non-metastatic atypical lipomatous tumors (ALT) or well-differentiated liposarcomas (WDLS) to high-grade tumors such as pleomorphic liposarcomas, which have a real risk of developing distant metastases (3-5).

The most common subtype in the liposarcoma family is ALT, which accounts for about $40-45 \%(5,6)$, and arises, without sex predilection, most frequently in the sixth decade of life, and can potentially be located in any region, with slight prevalence in the deep soft tissues of the limbs, especially in the thigh.

The term 'atypical lipomatous tumor' is usually preferred to cases where the neoplasia is localized in the limbs, and the definition 'well-differentiated liposarcoma' is preferably used for tumors localized in the retroperitoneum or in the mediastinum. Biologically, this tumor is a locally aggressive subtype, without metastatic potential, unless areas of 
dedifferentiation are present; from the diagnostic point of view, it is definitely a challenge, because it presents morphological and histological characteristics that are partly shared with both forms of benign and malignant lesions, thus requiring careful consideration in order to provide correct clinical management.

The clinical presentation of adipocytic tumors, as well as for most soft-tissue tumors, can vary from totally asymptomatic cases to cases in which the patient complains of pain, which is linked to the mass effect of the tumor, and to cases in which the presence of the tumor can cause symptoms secondary to compression of other anatomical structures, such as vessels, nerves or ducts.

Essentially, clinical examination seeks to assess the clinical aspects of benign or malignant masses, such as consistency (generally tense/elastic in benign and harsh in malignant forms), mobility (usually elevated in benign and low in malignant forms), size and location (bearing in mind that the deep masses are much more frequently malignant). Following physical examination, the doctor plans the proper diagnostic path, which will likely include an instrumental examination.

Imaging offers a wide range of diagnostic tools, but the reference examination for diagnosis, characterization and locoregional staging is magnetic resonance imaging (MRI). This method is the most suitable in the oncosurgical followup, as it is most reliable in defining the presence of postsurgical complications, response to medical therapy or relapse in regional disease.

With this method, the most accurate diagnosis can be obtained, meaning the ability to distinguish benign from malignant forms and a relationship of the lesion with the surrounding structures, is of paramount importance in the planning of surgery. It is also possible to recognize signs that can orient towards one subtype or other type of sarcoma, although today this is still an ambitious, but difficult to reach, goal (7). However, what this method allows, and what the radiologist is required to analyze, is the display of different signs that can indicate the malignancy of lesions, such as the presence of lesions $>5 \mathrm{~cm}$, deep-sited lesions, with inhomogeneous signal (especially in fluid-sensitive sequences), or the presence of septa $>2 \mathrm{~mm}$, with contrast-enhancement, or nodules (Figures 1 and 2). Of fundamental importance is the evaluation of lesion's relationship with the surrounding structures, because this becomes an essential parameter for evaluating the operability of these lesions (Figure 3 ).

However, at present, the gold standard for diagnosis of lipomatous tumors is histological evaluation, on the basis of specimens from core needle biopsy, possibly guided radiologically or with ultrasound.

Differentiation of the various histological types of liposarcoma is not always easy, even for the experienced pathologist, especially when only little tissue is available.
Particular difficulty is encountered in the differentiation between lipomas and ALT/WDLS, which is essential for the proper management of the patient. Generally, the distinction can be made because ALT/WDLS are mature adipocytic neoplasms with hyperchromatic nuclei; however, atypical stromal cells are not always easily recognizable, and can sometimes require very extensive sampling of the tumor. This critical issue sometimes makes it impossible to diagnosis with core needle biopsy only, which in some cases can lead to underdiagnosing of the tumor, not highlighting any atypia.

Some scientific advances have allowed a more accurate distinction, such as immunohistochemistry, reverse transcriptase-polymerase chain reaction (RT-PCR), fluorescence in situ hybridation (FISH), and antibodies to mouse double minute 2 (MDM2) and cyclin-dependent kinase 4 (CDK4). In particular, MDM2 has been identified as the gene most frequently amplified in ALT/WDLS. Others, however, have found a trend for overdiagnosis as a result of excessive use of immunohistochemistry, which should be reserved for doubtful forms, such as tumors $>15 \mathrm{~cm}$ without cytologically demonstrated atypia or cancer with questionable cytologic atypia (8). Therefore, a multidisciplinary approach (clinical-radiological -pathological) is essential for the best diagnostic classification of these tumors.

Recent studies have highlighted that experienced examiners are able to achieve high diagnostic accuracy in distinguishing between lipomas and ALT/WDLS on the basis of MRI characteristics, particularly considering size, margins, homogeneity of the signal [especially in T2weighted (T2W) sequences with fat suppression] and the presence of septa or nodules (9).

Recent literature has emphasized on the need to centralize the management of these patients in highly specialized centers, showing how the different experience of various centers can significantly change the outcome of these patients (10). This is because these are rare neoplasms, not easy to handle in either the diagnostic framework or oncosurgical management, and possible neoadjuvant therapy and choice of surgical intervention most likely to ensure radicality need to be considered. At a highly specialized center, a multidisciplinary team of different specialists, composed of surgeons, oncologists, radiologists and pathologists, all dedicated to these pathologies, meet regularly to discuss cases both in the initial stage (to define the diagnostic and therapeutic pathway) and after treatment (follow-up). Therefore, sending patients with recent onset or modification of swelling of probable relevance for soft tissue to a highly specialized center is the best option for the management of the patient.

The aim of this study was to compare the diagnostic accuracy of MRI assessment with the histological report of the surgical specimen. Another aim was to evaluate the diagnostic 

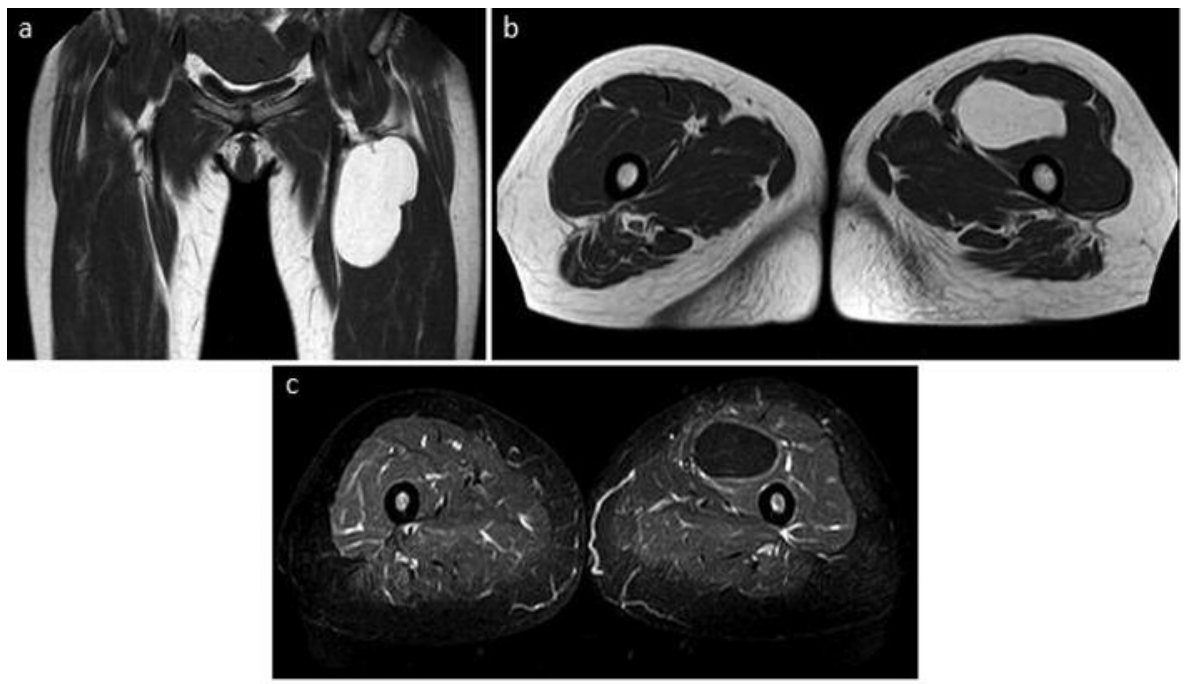

Figure 1. Lipoma in the root of the left thigh, coronal (a) and axial T1-weighted (b), short tau inversion recovery axial (c). Note the absence of septa and nodules, the signal homogeneity, and the type of expansive but not infiltrative growth.
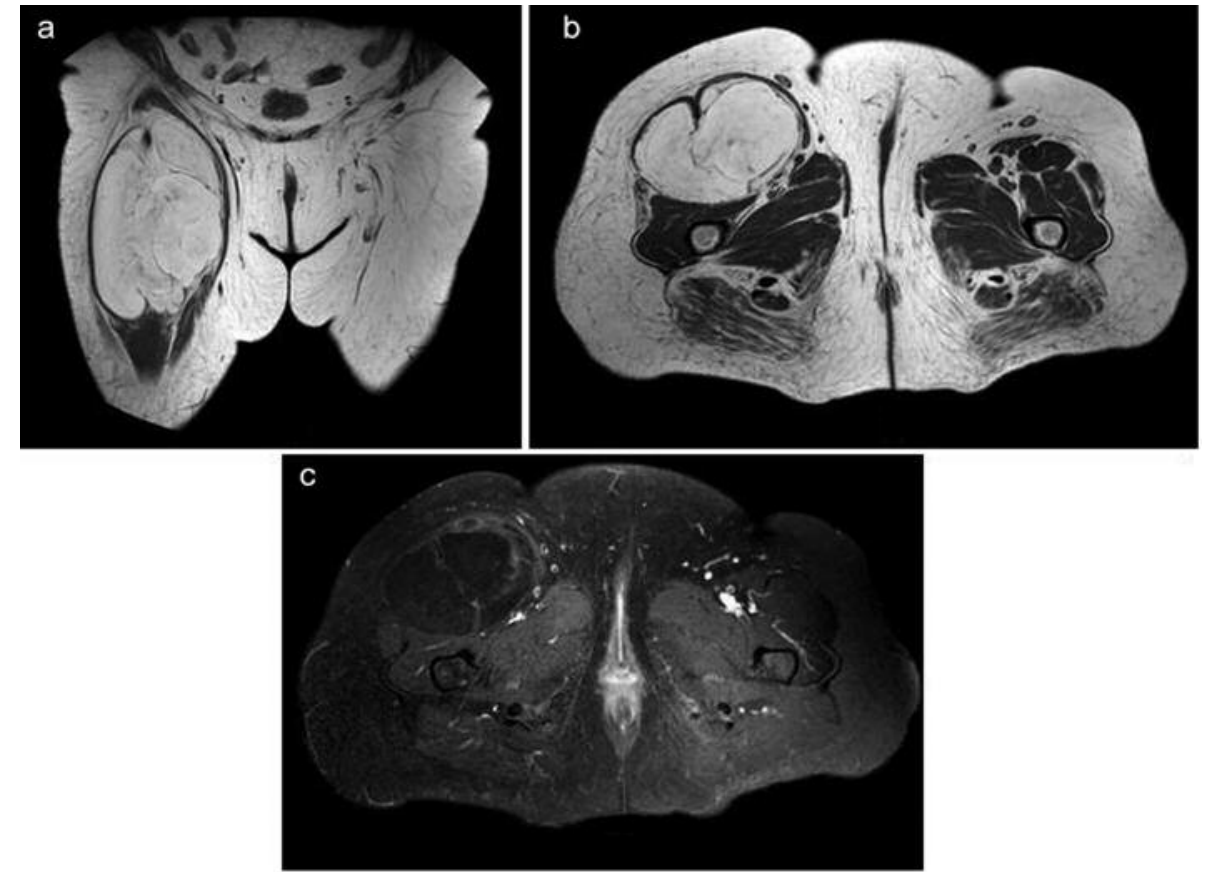

Figure 2. Atypical lipomatous tumor in the root of the right thigh, coronal (a) and axial T1-weighted (b), short tau inversion recovery axial (c). Note the presence of septa in the context of the lesion, which does not present exclusively fat content.

accuracy of two observers with similar expertise in soft-tissue sarcoma, in distinguishing between lipomas and ALT/WDLS, and in distinguishing between lipomas and liposarcomas. The secondary purpose was to try to identify a correlation for each MRI parameter (size, depth, septa, nodules, signal homogeneity) with benign or malignant lesions.

\section{Materials and Methods}

In the period between June 2011 and December 2014, 183 patients diagnosed with lipoma or liposarcoma at analysis of the surgical specimen were treated and studied. Patients were excluded if documentation was not available (MRI not available or unoperated 

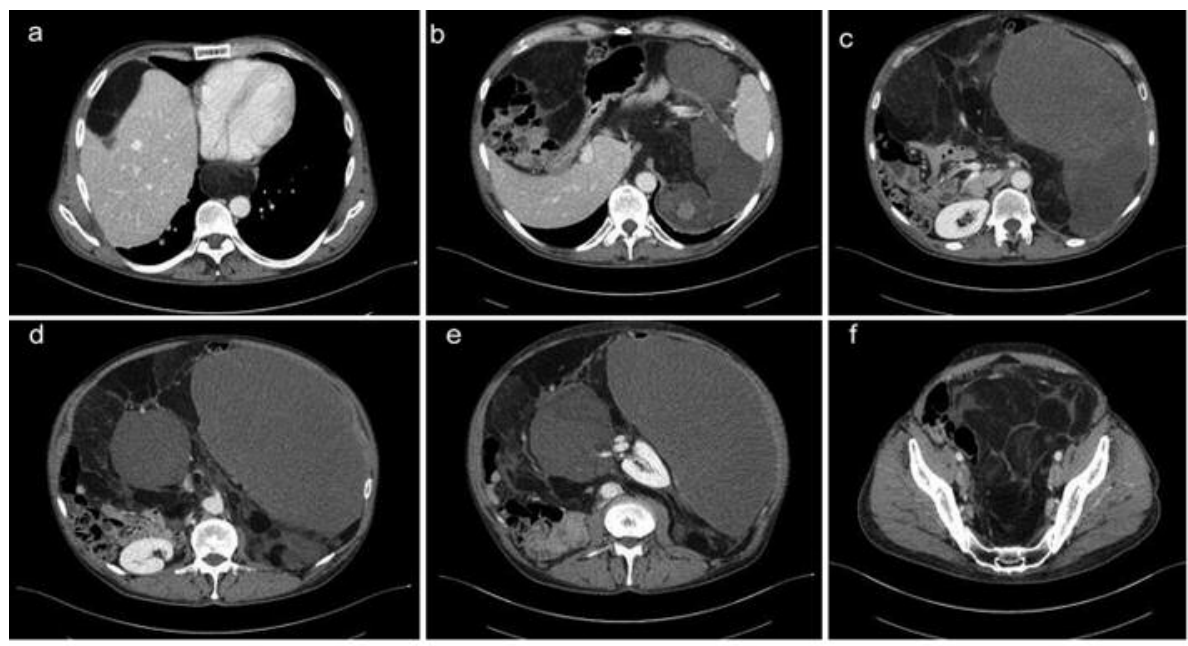

Figure 3. Dedifferentiated retroperitoneal liposarcoma, with extension in the posterior mediastinum. a: liposarcoma anterior to the liver, and extension in the posterior mediastinum; $b-e$ : abdominal extension of the dedifferentiated liposarcoma, with both lipomatous and solid components; $f:$ pelvic extension of the liposarcoma.

lesions). A total of 54 patients were included in the study ( 28 men, 26 women), with a mean age of 56 (range=27-84) years; radiological documentation (MRI) and histological examination of the surgical specimen were available for all 54. The patients were all followed-up from diagnosis to therapy by the Soft-tissue Sarcoma Multidisciplinary Group; each case was evaluated by a team of radiologists, surgeons, oncologists, radiotherapists, pathologists and orthopedists. All patients had a diagnostic hypothesis of either lipoma ALT or liposarcoma, on the basis of the analysis of these parameters and experience.

Since the MRI examinations were not performed with the same protocol or with the same equipment, the $\mathrm{T} 1 \mathrm{~W}$ and $\mathrm{T} 2 \mathrm{~W}$ sequences, sequences with fat suppression (STIR/T2 fat sat) and post contrast T1W were analyzed. The following MRI parameters were evaluated: Size: $\leq 5 \mathrm{~cm}$ or $>5 \mathrm{~cm}$; Location: superficial or deep to the fascia (retroperitoneal localization was considered deep); septa: $\leq 2 \mathrm{~mm}$ or $>2 \mathrm{~mm}$; nodules: present or absent; signal homogeneity.

All evaluations were performed blindly: two medical doctors carried out the investigation of cases and the adequacy of the documentation available, another two, with extensive experience of soft-tissue tumors, carried out the evaluation of the images without knowing the outcome of the histological analysis. The correlation between the diagnostic hypothesis and the individual marks of the two operators, and the correlation between diagnostic hypothesis of the operators and the histology of the surgical specimen were evaluated with Cohen's kappa (к). Statistical significance was considered for values of $p<0.05$.

Considering the dichotomous diagnosis (benign vs.malignant), the correlation between radiological diagnosis and definitive diagnosis (Fisher's exact test), sensitivity, specificity, positive predictive value (PPV) and negative predictive value (NPV) of the MRI-based diagnostic hypotheses were evaluated. These values were also calculated for individual MRI marks that were statistically correlated with benign or malignant lesions. The diagnostic accuracy of MRI in discriminating between benign and malignant forms, and between benign (lipomas) and low-grade malignancy forms (ALT/WDLS)
Table I. Degree of correlation according to the value of Cohen's $k$.

\begin{tabular}{lc}
\hline $\mathrm{K}$ & Correlation \\
\hline$<0.01$ & None \\
$0.01-0.2$ & Poor \\
0.201 .0 .4 & Low \\
$0.401-0.6$ & Moderate \\
$0.601-0.8$ & Good \\
$0.801-1$ & Excellent \\
\hline
\end{tabular}

were evaluated on the surgical specimen (Fisher's exact test). Finally, the correlation between individual MRI markers and benign or malignant lesions was assessed for the surgical specimen (Fisher's exact test),the strength of the association between the various signs and histology [odds ratio (OR)], and considering the $\mathrm{K}$ correlation according to the levels indicated in Table I.

Statistical analysis was performed with SAS software, version 9.3. (SAS Institute, Cary, NC, USA).

\section{Results}

A total of 54 patients were examined, of whom eight $(14.8 \%)$ with a diagnosis of lipoma (benign) and $46(85.2 \%)$ diagnosed with liposarcoma, of which 14 (30.4\%) were ALT, $11(23.9 \%)$ dedifferentiated, $12(26.1 \%)$ pleomorphic, and nine $(19.6 \%)$ myxoid.

Radiological signs are reported in Table II; in particular nine (16.6\%) patients had a lesion $\leq 5 \mathrm{~cm}$ and $45(83.4 \%)>5 \mathrm{~cm} ; 10$ $(18.5 \%)$ were aged $<50$ years and $44(81.5 \%) \geq 50$ years; three (5.6\%) patients had a superficial lesion and 51 (94.4\%) deep; 
Table II. Evaluation of individual magnetic resonance imaging signs, diagnostic hypotheses made by the radiologists and histological diagnosis.

\begin{tabular}{|c|c|c|c|c|c|c|c|c|c|c|c|c|c|c|}
\hline \multirow[b]{2}{*}{ Patient } & \multicolumn{2}{|c|}{$\begin{array}{l}\text { Lesion } \\
\text { size, } \mathrm{cm}\end{array}$} & \multicolumn{2}{|c|}{$\begin{array}{l}\text { Age, } \\
\text { years }\end{array}$} & \multicolumn{2}{|c|}{ Site } & \multicolumn{2}{|c|}{ Septa, mm } & \multicolumn{2}{|c|}{ Nodules } & \multirow[b]{2}{*}{ Homogeneous } & \multirow[b]{2}{*}{ Inhomogeneous } & \multicolumn{2}{|c|}{ Diagnosis } \\
\hline & $\leq 5$ & $>5$ & $<50$ & $>50$ & Superficial & Deep & $\leq 2$ & $>2$ & Yes & No & & & Radiological & Histological \\
\hline 1 & & $\mathrm{X}$ & & $\mathrm{X}$ & & $\mathrm{X}$ & & $\mathrm{X}$ & $\mathrm{X}$ & & & $\mathrm{X}$ & Liposarcoma & Liposarcoma \\
\hline 2 & & $\mathrm{X}$ & & $\mathrm{X}$ & & $\mathrm{X}$ & & $\mathrm{X}$ & $X$ & & & $\mathrm{X}$ & Liposarcoma & Liposarcoma \\
\hline 3 & & $X$ & & $X$ & & $\mathrm{X}$ & $X$ & & & $\mathrm{X}$ & $\mathrm{X}$ & & ALT & ALT \\
\hline 4 & & $\mathrm{X}$ & & $\mathrm{X}$ & & $\mathrm{X}$ & & $\mathrm{X}$ & & $\mathrm{X}$ & & $\mathrm{X}$ & Liposarcoma & Liposarcoma \\
\hline 5 & & $\mathrm{X}$ & & $\mathrm{X}$ & & $\mathrm{X}$ & & $\mathrm{X}$ & & $\mathrm{X}$ & & $X$ & Liposarcoma & Liposarcoma \\
\hline 6 & & $\mathrm{X}$ & $\mathrm{X}$ & & & $\mathrm{X}$ & $\mathrm{X}$ & & & $\mathrm{X}$ & & $\mathrm{X}$ & ALT & ALT \\
\hline 7 & & $\mathrm{X}$ & & $\mathrm{X}$ & & $\mathrm{X}$ & $\mathrm{X}$ & & & $\mathrm{X}$ & & $X$ & Lipoma & Lipoma \\
\hline 8 & & $\mathrm{X}$ & & $\mathrm{X}$ & & $\mathrm{X}$ & $\mathrm{X}$ & & $X$ & & & $\mathrm{X}$ & Liposarcoma & Liposarcoma \\
\hline 9 & & $X$ & $\mathrm{X}$ & & $X$ & & & $\mathrm{X}$ & $\mathrm{X}$ & & & $\mathrm{X}$ & Liposarcoma & Liposarcoma \\
\hline 10 & & $\mathrm{X}$ & & $X$ & & $\mathrm{X}$ & $\mathrm{X}$ & & & $\mathrm{X}$ & $\mathrm{X}$ & & ALT & ALT \\
\hline 11 & & $X$ & & $X$ & & $\mathrm{X}$ & $\mathrm{X}$ & & & $\mathrm{X}$ & & $X$ & Liposarcoma & Liposarcoma \\
\hline 12 & & $X$ & & $\mathrm{X}$ & & $\mathrm{X}$ & $\mathrm{X}$ & & $X$ & & & $\mathrm{X}$ & Liposarcoma & Liposarcoma \\
\hline 13 & $\mathrm{X}$ & & & $\mathrm{X}$ & & $\mathrm{X}$ & $\mathrm{X}$ & & & $\mathrm{X}$ & $\mathrm{X}$ & & Liposarcoma & Liposarcoma \\
\hline 14 & & $X$ & & $\mathrm{X}$ & & $\mathrm{X}$ & & $\mathrm{X}$ & $X$ & & & $X$ & Liposarcoma & Liposarcoma \\
\hline 15 & & $X$ & $\mathrm{X}$ & & & $\mathrm{X}$ & & $\mathrm{X}$ & $\mathrm{X}$ & & & $\mathrm{X}$ & Liposarcoma & Liposarcoma \\
\hline 16 & & $X$ & & $X$ & & $X$ & $\mathrm{X}$ & & & $\mathrm{X}$ & & $X$ & Liposarcoma & Liposarcoma \\
\hline 17 & & $\mathrm{X}$ & & $\mathrm{X}$ & & $\mathrm{X}$ & $\mathrm{X}$ & & & $\mathrm{X}$ & & $\mathrm{X}$ & ALT & ALT \\
\hline 18 & & $X$ & & $\mathrm{X}$ & & $X$ & $\mathrm{X}$ & & & $\mathrm{X}$ & & $X$ & ALT & ALT \\
\hline 19 & & $\mathrm{X}$ & & $\mathrm{X}$ & & $\mathrm{X}$ & $\mathrm{X}$ & & & $\mathrm{X}$ & & $\mathrm{X}$ & ALT & ALT \\
\hline 20 & & $X$ & & $X$ & & $\mathrm{X}$ & $\mathrm{X}$ & & & $\mathrm{X}$ & & $X$ & Liposarcoma & Liposarcoma \\
\hline 21 & $\mathrm{X}$ & & $\mathrm{X}$ & & & $\mathrm{X}$ & $\mathrm{X}$ & & & $\mathrm{X}$ & & $\mathrm{X}$ & Liposarcoma & Liposarcoma \\
\hline 22 & $\mathrm{X}$ & & & $\mathrm{X}$ & & $\mathrm{X}$ & $\mathrm{X}$ & & & $\mathrm{X}$ & & $X$ & Liposarcoma & Liposarcoma \\
\hline 23 & & $\mathrm{X}$ & $\mathrm{X}$ & & & $\mathrm{X}$ & $\mathrm{X}$ & & & $\mathrm{X}$ & $\mathrm{X}$ & & Lipoma & Lipoma \\
\hline 24 & & $X$ & & $\mathrm{X}$ & & $\mathrm{X}$ & $\mathrm{X}$ & & & $\mathrm{X}$ & & $\mathrm{X}$ & Liposarcoma & ALT \\
\hline 25 & & $\mathrm{X}$ & $\mathrm{X}$ & & & $\mathrm{X}$ & $\mathrm{X}$ & & & $\mathrm{X}$ & & $\mathrm{X}$ & Liposarcoma & Liposarcoma \\
\hline 26 & & $\mathrm{X}$ & $\mathrm{X}$ & & & $\mathrm{X}$ & $\mathrm{X}$ & & & $\mathrm{X}$ & & $\mathrm{X}$ & Liposarcoma & Liposarcoma \\
\hline 27 & $\mathrm{X}$ & & & $\mathrm{X}$ & & $\mathrm{X}$ & $\mathrm{X}$ & & & $\mathrm{X}$ & $\mathrm{X}$ & & Lipoma & Lipoma \\
\hline 28 & $\mathrm{X}$ & & & $\mathrm{X}$ & & $\mathrm{X}$ & $\mathrm{X}$ & & $\mathrm{X}$ & & & $\mathrm{X}$ & Liposarcoma & Liposarcoma \\
\hline 29 & & $X$ & & $\mathrm{X}$ & & $\mathrm{X}$ & $\mathrm{X}$ & & & $\mathrm{X}$ & & $\mathrm{X}$ & ALT & ALT \\
\hline 30 & & $X$ & & $\mathrm{X}$ & & $\mathrm{X}$ & $\mathrm{X}$ & & $X$ & & & $X$ & Liposarcoma & Liposarcoma \\
\hline 31 & & $X$ & & $\mathrm{X}$ & & $\mathrm{X}$ & $\mathrm{X}$ & & & $\mathrm{X}$ & & $X$ & ALT & ALT \\
\hline 32 & & $X$ & $\mathrm{X}$ & & $X$ & & $\mathrm{X}$ & & & $\mathrm{X}$ & & $\mathrm{X}$ & ALT & Lipoma \\
\hline 33 & & $X$ & & $X$ & & $\mathrm{X}$ & & $\mathrm{X}$ & & $\mathrm{X}$ & & $X$ & Liposarcoma & Liposarcoma \\
\hline 34 & & $\mathrm{X}$ & & $\mathrm{X}$ & & $\mathrm{X}$ & $\mathrm{X}$ & & & $\mathrm{X}$ & & $\mathrm{X}$ & ALT & Lipoma \\
\hline 35 & & $X$ & & $\mathrm{X}$ & & $X$ & & $X$ & $\mathrm{X}$ & & & $X$ & Liposarcoma & Liposarcoma \\
\hline 36 & & $\mathrm{X}$ & $\mathrm{X}$ & & & $\mathrm{X}$ & $\mathrm{X}$ & & & $\mathrm{X}$ & & $\mathrm{X}$ & ALT & ALT \\
\hline 37 & & $X$ & & $X$ & & $\mathrm{X}$ & & $\mathrm{X}$ & $\mathrm{X}$ & & & $X$ & Liposarcoma & Liposarcoma \\
\hline 38 & & $X$ & & $\mathrm{X}$ & & $\mathrm{X}$ & & $\mathrm{X}$ & & $\mathrm{X}$ & & $\mathrm{X}$ & Liposarcoma & Liposarcoma \\
\hline 39 & & $\mathrm{X}$ & & $\mathrm{X}$ & & $\mathrm{X}$ & & $\mathrm{X}$ & & $\mathrm{X}$ & & $\mathrm{X}$ & Liposarcoma & Liposarcoma \\
\hline 40 & & $\mathrm{X}$ & & $\mathrm{X}$ & & $\mathrm{X}$ & $\mathrm{X}$ & & & $\mathrm{X}$ & & $X$ & Liposarcoma & Liposarcoma \\
\hline 41 & $\mathrm{X}$ & & & $\mathrm{X}$ & & $\mathrm{X}$ & $\mathrm{X}$ & & & $\mathrm{X}$ & $\mathrm{X}$ & & ALT & ALT \\
\hline 42 & $\mathrm{X}$ & & & $\mathrm{X}$ & $X$ & & $\mathrm{X}$ & & & $\mathrm{X}$ & & $X$ & Liposarcoma & Liposarcoma \\
\hline 43 & & $X$ & & $\mathrm{X}$ & & $\mathrm{X}$ & & $\mathrm{X}$ & & $\mathrm{X}$ & & $\mathrm{X}$ & Liposarcoma & Liposarcoma \\
\hline 44 & & $\mathrm{X}$ & & $\mathrm{X}$ & & $\mathrm{X}$ & $\mathrm{X}$ & & & $\mathrm{X}$ & & $\mathrm{X}$ & ALT & ALT \\
\hline 45 & & $\mathrm{X}$ & $\mathrm{X}$ & & & $\mathrm{X}$ & & $\mathrm{X}$ & & $\mathrm{X}$ & & $\mathrm{X}$ & ALT & ALT \\
\hline 46 & & $X$ & & $\mathrm{X}$ & & $\mathrm{X}$ & $\mathrm{X}$ & & $\mathrm{X}$ & & & $X$ & Liposarcoma & Liposarcoma \\
\hline 47 & & $X$ & & $X$ & & $\mathrm{X}$ & $\mathrm{X}$ & & & $\mathrm{X}$ & $\mathrm{X}$ & & Lipoma & Lipoma \\
\hline 48 & & $X$ & & $\mathrm{X}$ & & $\mathrm{X}$ & & $\mathrm{X}$ & $\mathrm{X}$ & & & $\mathrm{X}$ & Liposarcoma & Liposarcoma \\
\hline 49 & $\mathrm{X}$ & & & $\mathrm{X}$ & & $\mathrm{X}$ & $\mathrm{X}$ & & & $\mathrm{X}$ & $\mathrm{X}$ & & ALT & ALT \\
\hline 50 & & $X$ & & $X$ & & $\mathrm{X}$ & $X$ & & $\mathrm{X}$ & & & $X$ & Liposarcoma & Liposarcoma \\
\hline 51 & & $\mathrm{X}$ & & $\mathrm{X}$ & & $\mathrm{X}$ & & $\mathrm{X}$ & & $\mathrm{X}$ & & $\mathrm{X}$ & Liposarcoma & Liposarcoma \\
\hline 52 & & $\mathrm{X}$ & & $\mathrm{X}$ & & $\mathrm{X}$ & $\mathrm{X}$ & & & $\mathrm{X}$ & $\mathrm{X}$ & & Lipoma & Lipoma \\
\hline 53 & & $\mathrm{X}$ & & $\mathrm{X}$ & & $\mathrm{X}$ & & $X$ & $\mathrm{X}$ & & & $\mathrm{X}$ & Liposarcoma & Liposarcoma \\
\hline 54 & $X$ & & & $X$ & & $\mathrm{X}$ & $\mathrm{X}$ & & & $\mathrm{X}$ & $\mathrm{X}$ & & Lipoma & Lipoma \\
\hline
\end{tabular}

ALT, Atypical lipomatous tumor. 
Table III. Radiological evaluation of malignancy or benignity and corresponding histological diagnosis.

\begin{tabular}{lccc}
\hline & \multicolumn{2}{c}{ Histological diagnosis, $\mathrm{n}$} & $\mathrm{N}$ \\
\cline { 2 - 3 } Radiological diagnosis & Liposarcoma & Lipoma & Total \\
\hline Liposarcoma & 46 & 2 & 48 \\
Lipoma & 0 & 6 & 6 \\
Total & 46 & 8 & 54 \\
\hline
\end{tabular}

$37(68.5 \%)$ lesions did not contain septa $>2 \mathrm{~mm}$, whereas 17 $(31.5 \%)$ did; $39(72.2 \%)$ lesions did not contain solid nodules, whereas $15(27.8 \%) \mathrm{did}$; and $10(18.5 \%)$ lesions had a homogeneous signal and $44(81.5 \%)$ an inhomogeneous signal.

Both examiners found the same radiological signs, with total $(100 \%)$ agreement. Interoperator correlation of the diagnostic hypotheses of the two examiners was also total (100\%).

The concordance of the radiological diagnosis with the definitive diagnosis was high (Table III), with a $\mathrm{k}$ value of 0.99 and a $95 \%$ confidence interval (CI) of $0.79-1$; the correlation between the dichotomous radiological diagnosis (benign $v s$. malignant) and dichotomous definitive diagnosis using Fisher's exact test was statistically significant $(p<0.05)$, with sensitivity in detecting cases of malignancy of $100 \%$, specificity of $75 \%$, a PPV of $96 \%$ and NPV of $100 \%$.

The correlation of the differential diagnosis of lipoma and ALT/WDLS (Table IV) using the Fisher exact test was statistically significant $(p<0.05)$, with sensitivity in detecting cases of malignancy of $100 \%$, specificity of $75 \%$, a PPV of $87 \%$ and NPV of $100 \%$.

Not all radiological signs were significantly associated with malignancy, in particular, the size and age did not have a statistically significant relationship, the site had a correlation but with limited power $(p=0.39)$, the presence of nodules had a borderline significant correlation $(p=0.09)$, while the presence of septa $>2 \mathrm{~mm}$ and inhomogeneity were significantly correlated with malignancy $(p<0.05)$.

Regarding the strength of the association (Table V), lesion dimensions, age, the site, septa and nodules were not significant; homogeneity was significantly associated with malignancy. The sensitivity of the sign "septa" was $37 \%$, with specificity of $100 \%$, PPV of $100 \%$ and NPV of $21.6 \%$. The sensitivity of the sign homogeneity was $89 \%$, with specificity $62.5 \%$, PPV of $93 \%$ and NPV of $50 \%$.

\section{Discussion}

Lipomatous tumors are by far the most common of soft-tissue tumors, with various malignant potentials, from almost zero risk to high risk, and prognosis is therefore very variable.
Table IV. Radiological evaluation of lipoma and atypical lipomatous tumor (ALT)/well-differentiated liposarcomas (WDLS) and corresponding histological diagnosis.

\begin{tabular}{lccc}
\hline & \multicolumn{2}{c}{ Histological diagnosis, $\mathrm{n}$} & \\
\cline { 2 - 3 } Radiological diagnosis & ALT/WDLS & Lipoma & Total \\
\hline ALT/WDLS & 13 & 2 & 15 \\
Lipoma & 0 & 6 & 6 \\
Total & 13 & 8 & 21 \\
\hline
\end{tabular}

The crucial role of diagnostics is to correctly define the local and distal staging, and try as much as possible to guide the clinician in the proper management of the patient, trying also to provide information about the benign or malignant lesion. Many authors have tried to identify possible radiological, ultrasound and MRI signs that could indicate or at least suggest one or the other form, but to date, evidence that shows that only imaging can distinguish between benign or malignant is still insufficient.

Some signs have long been recognized as being suggestive of malignant forms, such as the presence of septa $>2 \mathrm{~mm}$, intralesional nodules, and the inhomogeneity of the signal (11); the results of this study are partially consistent with the literature. In particular, a statistically significant association between the presence of septa $>2 \mathrm{~mm}$ and the inhomogeneity of the signal and the malignancy of the lesion $(p<0.05)$ was found. An important strength of the association between these signs and the malignancy of the lesion was also detected. In particular, it is interesting that all lesions with septa $\geq 2 \mathrm{~mm}$ were found to be malignant, and of 37 lesions with septa $<2 \mathrm{~mm}$, eight $(17.4 \%)$ were benign and 29 $(82.6 \%)$ malignant. A moderate association with presence of nodules and the site of the lesion and malignancy $(p=0.09$ and $p=0.39$, respectively) was found, whereas there was no association with other radiological signs. Homogeneity of the signal was proven to be more closely associated with the malignancy of the lesion $(p<0.005)$. Note also that the importance of the NPV of this parameter $(50 \%)$ emerges from the statistical analysis, and is seemingly low compared to the PPV (93\%). However, the distribution of the sample, greatly skewed in favor of cases of malignancy $(85.2 \%)$, shows how the information provided by the analysis of only one parameter of homogeneity increased the probability of a benign lesion compared to the prior probability (from $14.8 \%$ to $50 \%$ ).

It is noteworthy that three patients were assessed incorrectly, and all three were cases of overdiagnosis. If considering the ALT category as belonging to the group of liposarcomas, and therefore considering only the ability to distinguish between radiologically benign and malignant 
Table V. Association and strength of the association between clinical parameters or magnetic resonance imaging signs and benign or malignant lesions.

\begin{tabular}{|c|c|c|c|c|c|}
\hline Parameter & $\begin{array}{l}\text { Subgroup } \\
(\mathrm{n}=54)\end{array}$ & $\begin{array}{c}\text { Lipoma }(\mathrm{n}=8) \\
(14.8 \%)\end{array}$ & $\begin{array}{c}\text { Liposarcoma }(\mathrm{n}=46) \\
(85.2 \%)\end{array}$ & OR $(95 \% \mathrm{CI})$ & $p$-Value* \\
\hline \multirow[t]{2}{*}{ Dimensions } & $\leq 5 \mathrm{~cm}(\mathrm{n}=9)(16.6 \%)$ & $2(22.2 \%)$ & $7(77.8 \%)$ & Ref. & 0.61 \\
\hline & $>5 \mathrm{~cm}(\mathrm{n}=45)(83.4 \%)$ & $6(13.3 \%)$ & $39(86.7 \%)$ & $1.86(0.31-11.14)$ & \\
\hline \multirow[t]{2}{*}{ Age } & $\leq 50$ Years $(\mathrm{n}=10(18.1 \%)$ & $2(20 \%)$ & $8(80 \%)$ & Ref. & 0.63 \\
\hline & $>50$ Years $(\mathrm{n}=44(81.9 \%)$ & $6(13.6 \%)$ & $38(86.4 \%)$ & $1.58(0.27-9.32)$ & \\
\hline \multirow[t]{2}{*}{ Site } & Superficial $(n=3(5.6 \%)$ & $1(33.3 \%)$ & $2(66.7 \%)$ & Ref. & 0.39 \\
\hline & Deep $(n=51(94.4 \%)$ & $7(13.7 \%)$ & $44(86.3 \%)$ & $3.14(0.25-39.44)$ & \\
\hline \multirow[t]{2}{*}{ Septa } & $\leq 2 \mathrm{~mm}(\mathrm{n}=37(68.5 \%)$ & $8(21.6 \%)$ & $29(78.4 \%)$ & Ref. & $<0.05$ \\
\hline & $>2 \mathrm{~mm}(\mathrm{n}=17(31.5 \%)$ & $0(0 \%)$ & $17(100 \%)$ & $10.1(0.51-201)$ & \\
\hline \multirow[t]{2}{*}{ Nodules } & No $(n=39(72.2 \%)$ & $8(20.5 \%)$ & $31(79.5 \%)$ & Ref. & 0.09 \\
\hline & Yes $(n=15(27.8 \%)$ & $0(0 \%)$ & $15(100 \%)$ & $8.37(0.41-169.4)$ & \\
\hline \multirow[t]{2}{*}{ Homogeneity } & Yes $(n=10(18.1 \%)$ & $5(50 \%)$ & $5(50 \%)$ & Ref. & $<0.005$ \\
\hline & No $(n=44(83.4 \%)$ & $3(6.8 \%)$ & $41(93.2 \%)$ & $13.67(2.48-75.27)$ & \\
\hline
\end{tabular}

*Fisher's exact test.

lesions, cases of overdiagnosis are reduced to two. This, despite not having any clear statistical significance, can point-out the fact that the morphological aspects may give rise to false-positives, but, at least with regard to the series of this study, not false-negatives. In fact, analyzing the data of sensitivity, specificity and predictive value of radiological interpretation, it emerges that the sensitivity of the radiologists in identifying cases of benign and malignant tumors was very high, with $100 \%$ sensitivity and NPV. In our experience, we can say that the cases evaluated as benign have always been such. This finding may be particularly relevant to the management of the patient, because if confirmed by an evaluation of a larger sample or by other studies, it could make biopsy unnecessary in such patients, with a net reduction of costs, time and, not least, the psychological implications that any further diagnostic examination would have for patients. Information obtained from the MRI survey, in fact, could allow a patient with lipoma to be identified, then they could receive a reassuring prognosis (excellent in the case of lipoma, with low risk of local recurrence), and selection for a possible intervention of excision with adequate definition of the involvement of the surrounding anatomical structures.

A good result was also obtained in the differential diagnosis between radiological lipoma and ALT/WDLS, in which the correlation was statistically significant, although with a small sample. This supports the findings in the literature, and pushes us more and more to consider MRI as a cornerstone in the evaluation of these lesions.

To date, however, the final diagnosis is made on histological examination, but it is not always easy, especially in distinguishing between a benign lesion and one with a low potential for malignancy when the examination is performed on only one histological sample. For example, we must consider that the principal sign of differentiation of ALT/WDLS is the presence of a mature adipocyte proliferation, with a secure variation of cell size, with at least one focal nuclear atypia in fat cells. Nevertheless, an important diagnostic aid is the recognition of hyperchromatic stromal cells, which are more easily detected within the fibrous septa (12), not typically found in benign forms.

Precisely for this reason, biopsy may not be enough because if it is performed in an area without fibrous septa and where the homogeneous component of adipocytes prevails, there is the risk of underdiagnosis. Sometimes, especially before the frequent use of amplification of MDM2 gene, histological findings not suggestive of a precise form (e.g. "lipoma/ALT") were reported, due to the scantiness of the biopsy specimen. In this case, the integration between the pathologist and the radiologist is essential, because it is possible to arrive at a diagnosis with greater accuracy, combining the capabilities of two specialists.

Importantly, also in our series, two patients had a diagnosis different from that obtained with histological analysis, as a result of multidisciplinary discussion in which the comparison revealed the presence (in bulky tumor masses) of areas frankly inhomogeneous, with nodular aspects, when led to a diagnosis of WDLS with areas of dedifferentiation, rather than simple WDLS. These diagnoses were reaffirmed by local recurrences of aggressive forms about 12 months later, a biological behavior uncharacteristic of well-differentiated forms (Figure 4).

Of course, the extreme paucity of such cases, made more evident by the rarity of the tumors examined, cannot give statistically relevant data, but suggests critical consideration 

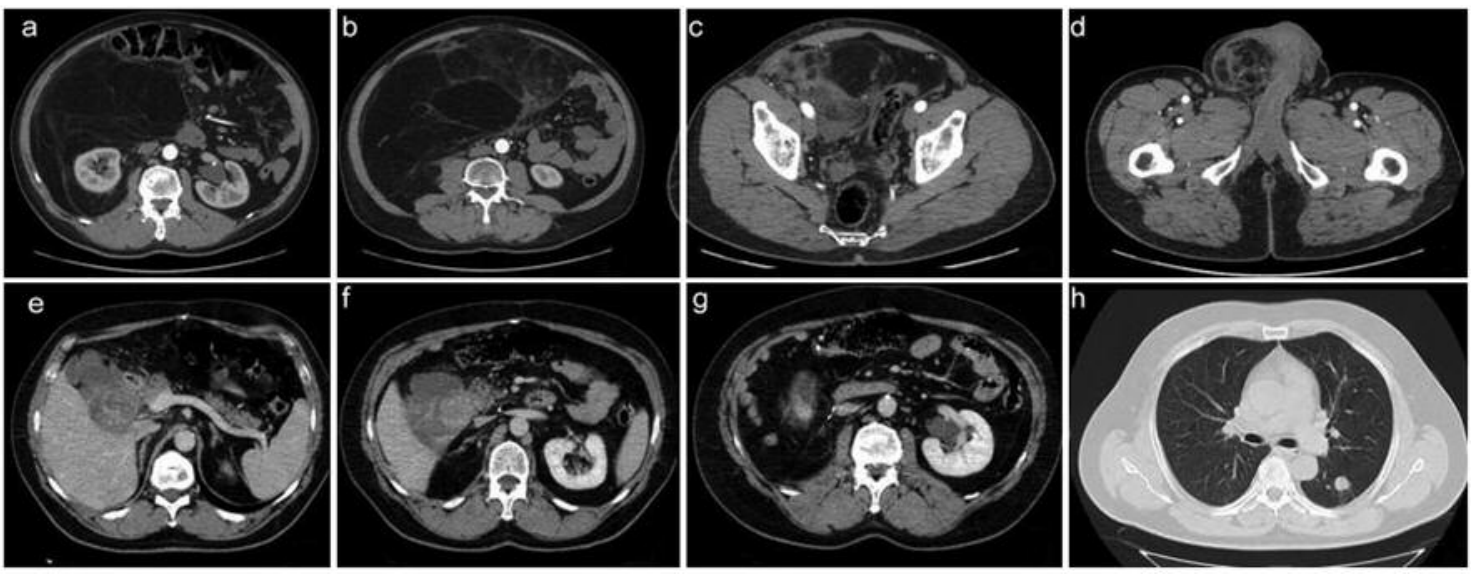

Figure 4. Foci of dedifferentiation $(a, b, c, d)$, initially operated and erroneously diagnosed as well-differentiated liposarcoma. Twelve months later, recurrence of differentiated liposarcoma $(e, f, g)$ with pulmonary metastases $(h)$ was diagnosed.

in the current diagnostic process and the still almost complete confidence in histology. It is in fact a priority, on the basis of our experience, that this be integrated with the radiological interpretation, since, especially for large lesions, it is possible that the sampling of the pathologist is unable to detect any foci of dedifferentiation, which would significantly change the management and prognosis of the patient; foci which also could easily be recognized by MRI or computed tomography.

Therefore, an important fact that emerges, in our view, is that the multidisciplinary approach is mandatory for these pathologies, beginning with diagnosis in order to avoid underdiagnosing forms with malignant potential, which, if not properly handled, may evolve or present as local recurrence or distant metastases.

Limitations of this study are the low number and distribution of benign and malignant cases, the latter contributing to the weaker statistical significance. This problem arises from the type of center where the data were collected: a regional referral center receiving the more difficult to manage cases, whereas frankly benign tumors are generally more easily managed by the peripheral centers. It is still our commitment to expand the series in time and to try to obtain as much relevant data as possible in order to contribute to a better management of patients with lipomatous tumors.

\section{Conflicts of Interest}

All authors declare that they have no conflict of interest.

\section{Compliance with Ethical Standards}

All procedures performed in studies involving human participants were in accordance with the ethical standards of the institutional and/or national research committee and with the 1964 Helsinki declaration and its later amendments or comparable ethical standards

Informed consent was obtained from all individual participants included in the study.

\section{References}

1 Murphey MD, Arcara LK and Fanburg-Smith J: imaging of musculoskeletal liposarcoma with radiologic-pathologic correlation. Radiographics 25: 1371-1395, 2005.

2 O'Regan KN, Jagannathan J, Krajewski K Zukotynski K, Souza $\mathrm{F}$, Wagner AJ and Ramaiya N: Imaging of liposarcoma: classification, patterns of tumor recurrence and response to treatment. Am J Roentgenol 197: 37-43, 2011.

3 Fletcher CDM, Bridge JA, Hogendoorn PCW and Mertens F (eds.): WHO Classification of Tumours of Soft Tissue and Bone, Fourth Edition. Lyon: IARC, 2013.

4 Christopher D, Unni K and Mertens F (eds.): WHO Classification of Tumors. Pathology and Genetics: Tumors of Soft Tissue and Bone. Chapter 1. Adipocytic tumors. Lyon, France: IARC, pp. 19-46, 2002.

5 Christopher D, Unni K and Mertens F (eds.): World Health Organization Classification of Tumors. Pathology and Genetics: Tumors of Soft Tissue and Bone. Liposarcoma of bone (in Chapter 13). Lyon, France: IARC, pp. 330, 2002.

6 Coindre JM, Pedeutour F and Aurias A: Well-differentiated and dedifferentiated liposarcomas. Virchows Arch 456: 167-179, 2011.

7 Stramare R, Beltrame V, Gazzola M, Sommavilla M, Gerardi M, Scattolin G, Faccinetto A, Rastrelli M, Grisan E, Montesco MC, Rossi CR and Rubaltelli L: Imaging of Soft-Tissue Tumors. J Magn Reson Imaging 23: 21-27, 2012.

8 Zhang $\mathrm{H}$, Erickson-Johnson $\mathrm{M}$, Wang X, Oliveira JL, Nascimento AG, Sim FH, Wenger DE, Zamolyi RQ, Pannain VL and Oliveira AM: Molecular testing for lipomatous tumors: critical analysis and test recommendations based on the analysis of 405 extremity-based tumors. Am J Surg Pathol 34: 13041311, 2010. 
9 O'Donnell PW, Griffin AM, Eward WC, Sternheim A, White LM, Wunder JS and Ferguson PC: Can experienced observers differentiate between lipoma and well differentiated liposarcoma using only MRI? Sarcoma 23: 12-35, 2013.

10 Rossi CR, Vecchiato A, Mastrangelo G, Montesco MC, Russano F, Mocellin S, Pasquali S, Scarzello G, Basso U, Frasson A, Pilati P, Nitti D, Lurkin A and Ray-Coquard I: Adherence to treatment guidelines for primary sarcomas affects patient survival: a side study of the European CONnective TIssue CAncer NETwork (CONTICANET). Ann Oncol 24: 168516-91, 2013.

11 Brisson M, Kashima T, Delaney D, Tirabosco R, Clarke A, Cro S, Flanagan AM and O'Donnell P: MRI characteristics of lipoma and atypical lipomatous tumor/well-differentiated liposarcoma: retrospective comparison with histology and MDM2 gene amplification. Skeletal Radiol 42: 635-647, 2013.

12 Rastrelli M, Tropea S, Basso U, Roma A, Maruzzo M and Rossi CR: Soft tissue limb and trunk sarcomas: diagnosis, treatment and follow-up. Anticancer Res 34: 5251-5262, 2014.

Received January 24, 2017

Revised April 3, 2017

Accepted April 4, 2017 